POLLACK PERIODICA

An International Journal for Engineering and Information Sciences

DOI: $10.1556 / 606.2017 .12 .2 .14$

Vol. 12, No. 2, pp. 163-172 (2017)

www.akademiai.com

\title{
INDOOR AIR QUALITY MEASUREMENTS IN HUNGARIAN RESIDENTIAL BUILDINGS
}

\author{
Julianna LIPTÁK-VÁRADI \\ Department of Interior Design, College of Engineering, Prince Sultan University \\ P.O. Box 66833 Rafha Street, 11586 Riyadh, Saudi Arabia \\ e-mail: jvaradi@psu.edu.sa
}

Received 9 December 2016; accepted 18 April 2017

\begin{abstract}
Indoor air quality is a major part of indoor environmental quality and plays an important role in creating sustainable and healthy indoor environments. Well-being, health and comfort are affected by indoor air quality. The measurements that are introduced in this research paper were used to record the results of three different residential interiors. These data are a part of a larger scale research project that included the evaluation of residential buildings, offices, university interiors and for instance nurseries. The reason behind conducting the measurements in these interiors was that in all of the examples inadequate indoor air quality and therefore human discomfort, illness and also building failure occurred.

In this paper the theoretical background of the research and the measurement of indoor air quality (indoor air temperature, relative humidity level and carbon dioxide level) will be introduced. The poor indoor air quality in these buildings is a result of a complex system. The thermal bridges of the facade cause cold interior surfaces, the airtight solutions cause high relative humidity levels. These two combined result in mould appearance. Besides, the lack of appropriate ventilation rate can be the third part of the reason behind poor indoor air quality.

Based on the results of the measurement data, different solutions are suggested in each case to improve indoor environmental and air quality, in accordance with creating healthier indoor environments.
\end{abstract}

Keywords: Indoor environmental quality, Indoor air quality, $\mathrm{CO}_{2}$ concentration, Air quality measurements, Residential interiors 


\section{Introduction}

Twenty-first century urbanites spend most of their lives in indoor spaces. The majority of people carry on $80-90 \%$ of their lives inside buildings, which must satisfy the objective and subjective requests linked to vital functions of the occupants [1]. Based on age, personal situation and other factors, these interior spaces are the workplaces, transportation vehicles, other public places and homes. More than a third of the daily lives are spent in residential interiors. People with special life circumstances: small children, parents with infants, sick or elderly people, remote or freelancer workers and housewives can spend even more time in residential interiors. Therefore urban planners and scientists from different disciplines have to face the challenge of creating livable urban environments [2].

The Indoor Environmental Quality (IEQ) performance of residential buildings hugely affects the health, productivity and well-being of building occupants, as well as lifecycle costs, and energy consumption [3]. In a study by Frontczak et al. [4] a chart can be found with data from different studies concerning the ranking of the importance of different environmental conditions for overall satisfaction with IEQ. More recently, research has been conducted, which understands the relationship between the built environment and humans as a complex interplay between building occupants and an array of physical, chemical, biological and design factors [5]. Several disciplines, e.g. engineering sciences, medical sciences, public health, occupational health, environmental psychology, and sociology examine the high impact psychosomatic, physiological and psychological effects have on human comfort and health within closed indoor spaces [6]. Thanks also to the green building movement; the focus has increasingly extended to issues of indoor environmental quality in relation to health and comfort of the indoor occupants [7].

Preliminary research studies have been focused on searching for solutions for existing problems, such as Sick Building Syndrome (SBS). In several studies, the focus is on single environmental factors and their effects, for instance the effect of lighting performance on the quality of interior spaces. Sun- or day lighting is a key to good energy performance, as well as occupant satisfaction, comfort, productivity and health [8]; however, sometimes it is neglected in an effort to achieve appropriate thermal comfort.

One major factor of the complex system of IEQ is Indoor Air Quality (IAQ). Gradual strengthening of the requirements on the level of energy performance has been in progress in the European Union, therefore also in Hungary, due to the need of energy saving for buildings [9]. The envelope retrofit of existing buildings and the construction methodology with high performance thermal insulation of newly built residential buildings result in the reduction of a natural exchange of the air even below the hygienic minimum [10]. This can result in poor IEQ and IAQ, decreased performance, or poor health conditions.

The present paper demonstrates examples of IAQ measurements in residential interiors located in Hungary. 


\section{Description of the investigated residential buildings}

The residential buildings and flats investigated in this study are located in Budapest, Hungary. The ventilation type of these apartments is natural ventilation (e.g. window opening); they are not equipped with mechanical ventilation system.

In all of these three apartments families are living with small children. The children are between ages 2-8. All of them have different respiratory symptoms, asthma or pseudo-croup. These symptoms might be related to poor IAQ of the given apartment. Therefore indoor air monitoring including the measurement of carbon-dioxide, relative humidity and indoor air temperature was conducted to collect more information about the IEQ and IAQ inside these homes. To respect the privacy of the inhabitants, the apartments will be referred to by code name only [11].

Table I shows the characteristics of these apartments. The first measurement was conducted in a newly built home. This apartment contains a living room and two smaller bedrooms, with small floor area, $53 \mathrm{~m}^{2}$, (see Fig. 1).

Table I

Characteristics of the residential homes (Apartment \#1, \#2 and \#3)

\begin{tabular}{|c|c|c|c|c|c|}
\hline & $\begin{array}{l}\text { Area } \\
{\left[\mathrm{m}^{2}\right]}\end{array}$ & $\begin{array}{c}\text { No. of } \\
\text { occupants }\end{array}$ & $\begin{array}{c}\text { Type of } \\
\text { construction }\end{array}$ & Insulation, air tightness & Problems \\
\hline \#1 & 53 & 4 & $\begin{array}{l}\text { Reinforced } \\
\text { concrete } \\
\text { frame with } \\
\text { hollow brick } \\
\text { infill walls } \\
\text { (built in } \\
\text { 2013) }\end{array}$ & $\begin{array}{l}\text { Highly insulated with } \\
\text { high performance } \\
\text { windows, but several } \\
\text { (interfering) thermal } \\
\text { bridges, air-tight } \\
\text { construction }\end{array}$ & $\begin{array}{l}\text { Asthma for } \\
\text { children, mold } \\
\text { at thermal } \\
\text { bridges, high } \\
\text { relative indoor } \\
\text { humidity }\end{array}$ \\
\hline \#2 & 65 & 4 & $\begin{array}{l}\text { Reinforced } \\
\text { concrete } \\
\text { sandwich } \\
\text { panels (built } \\
\text { in 1986) } \\
\end{array}$ & $\begin{array}{l}8 \mathrm{~cm} \text { insulation } \\
\text { between reinforced } \\
\text { concrete panels, not an } \\
\text { air tight construction }\end{array}$ & $\begin{array}{l}\text { Respiratory } \\
\text { illness of } \\
\text { children, } \\
\text { appearance of } \\
\text { mold }\end{array}$ \\
\hline \#3 & $\begin{array}{c}65+ \\
20 \\
\text { (two } \\
\text { levels, } \\
\text { roof } \\
\text { level) }\end{array}$ & 4 & $\begin{array}{l}\text { Reinforced } \\
\text { concrete } \\
\text { frame with } \\
\text { brick infill } \\
\text { walls, } \\
\text { wooden roof } \\
\text { structure } \\
\text { (built in } \\
\text { 1985) }\end{array}$ & $\begin{array}{l}\text { Without insulation, } \\
\text { detailed geometry, } \\
\text { several thermal bridges, } \\
\text { new windows result in } \\
\text { air tight construction }\end{array}$ & $\begin{array}{l}\text { Asthma for } \\
\text { children, mold } \\
\text { at thermal } \\
\text { bridges }\end{array}$ \\
\hline
\end{tabular}

The geometry of the floor plan is complex; therefore several thermal bridges occur and interact with each other. Besides, the new windows result in an airtight solution. The cold interior surfaces at the thermal bridges, combined with the high indoor relative humidity caused by the airtight construction result in mould appearance, not just at the thermal bridges, but also at different surfaces of the external wall. 


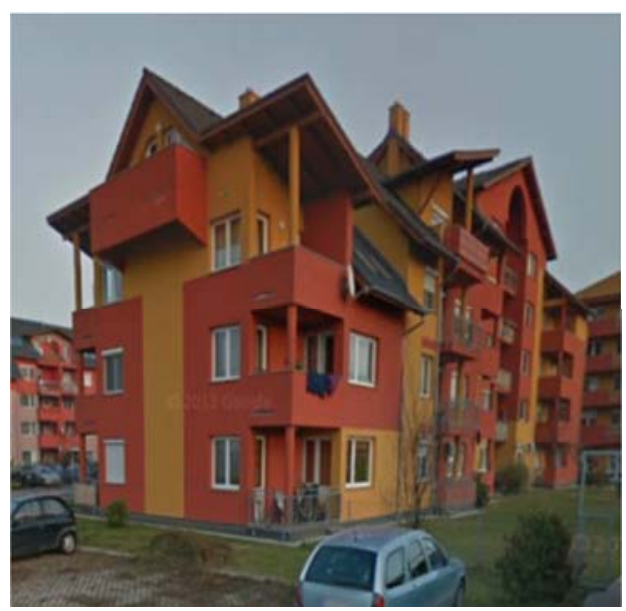

Fig. 1. Newly built multifamily residential building, where the first measurement was conducted

The second apartment (see Fig. 2) is located in a reinforced concrete building, which was built in 1986. Since the windows are the original wooden windows, natural infiltration occurs which helps in air exchange but results a bad performance from an acoustic point of view. The floor area is $65 \mathrm{~m}^{2}$, which is an average size for this type of residential home.

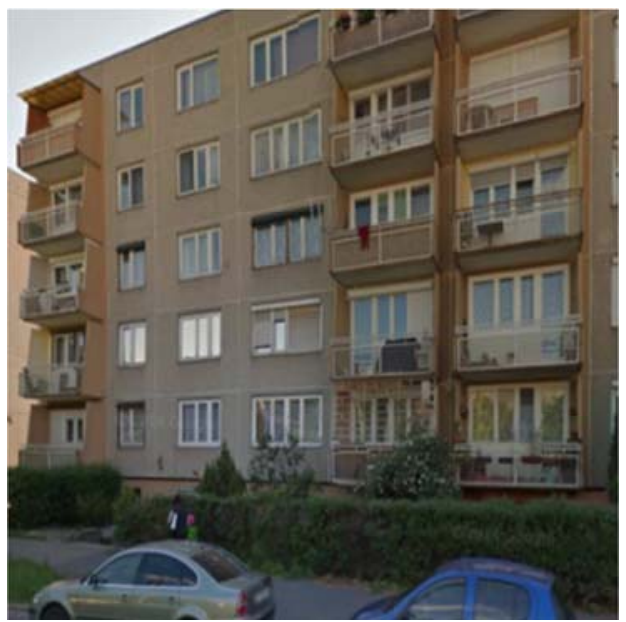

Fig. 2. Reinforced concrete multifamily residential building, where the second measurement was conducted

The third apartment is (see Fig. 3) is located below the sloped roof structure of a building built in 1985, with a basic floor area of $65 \mathrm{~m}^{2}$ and an additional $20 \mathrm{~m}^{2}$ room in the upper level. As with the first apartment, a complex floor plan (and roof structure) 
has resulted in several thermal bridges. At these places mould appeared in this apartment, also.

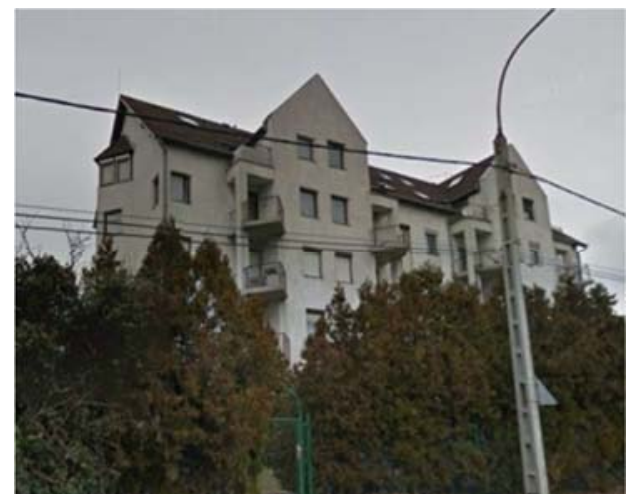

Fig. 3. Multifamily residential building with hollow brick infill wall, where the third measurement was conducted

It has to be mentioned here, that during IAQ measurements other parameters were also measured, including the quality of lighting and noise level. Post-occupancy survey was conducted, as well. These results are not evaluated at this stage, since the most urgent issue is to improve IAQ of these apartments.

\section{Indoor air quality - Measurement and method}

IAQ was measured using a Voltcraft CO Air-Quality Indicator (which measures carbon-dioxide, indoor air temperature and relative humidity levels) [12].

Measurements were conducted for several days, and data were taken both when the apartments were occupied (evenings, nights) and also when the apartments were empty. Useful information was gathered regarding not just the performance of the given interior in terms of basic air quality, but also about the relationship between occupant behavior and IAQ.

The limitations of these measurements relate to the fact that during the measurement process, only one air-quality indicator was available, so the data of the three different homes were taken on different weeks of the winter months. Therefore the slight differences in the weather might have affected the results. Furthermore, the equipment is not suitable for continuous (digital) recording of the results. These would not seem to be serious limitations for several reasons. First, records were taken during winter, when natural ventilation takes place only a few minutes each day. Second, when reading the results from the screen of the measurement equipment, the inhabitants wrote additional notes next to the results (e.g. time of window openings, number of occupants in the given interior, outdoor weather conditions). The occupants were asked to record the measurement values whenever there had been a change in the environment (e.g. window opening or arriving home). 


\section{Results and discussion}

Fig. 4 - Fig. 6 show the carbon-dioxide rates of the three residential interiors, measured by the air quality indicator. The measurement data show the results of one week period.

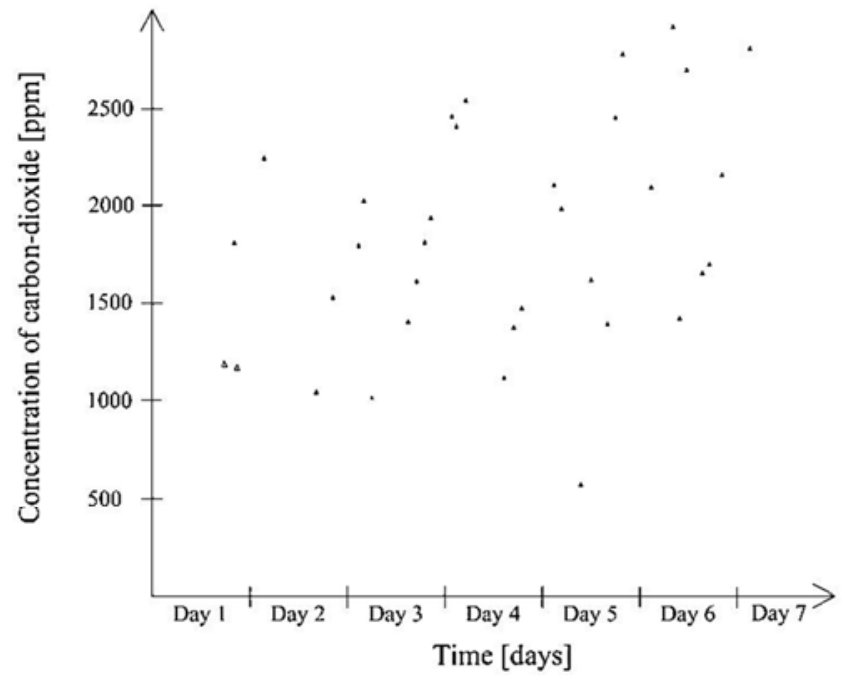

Fig. 4. Carbon-dioxide levels in Apartment \#1

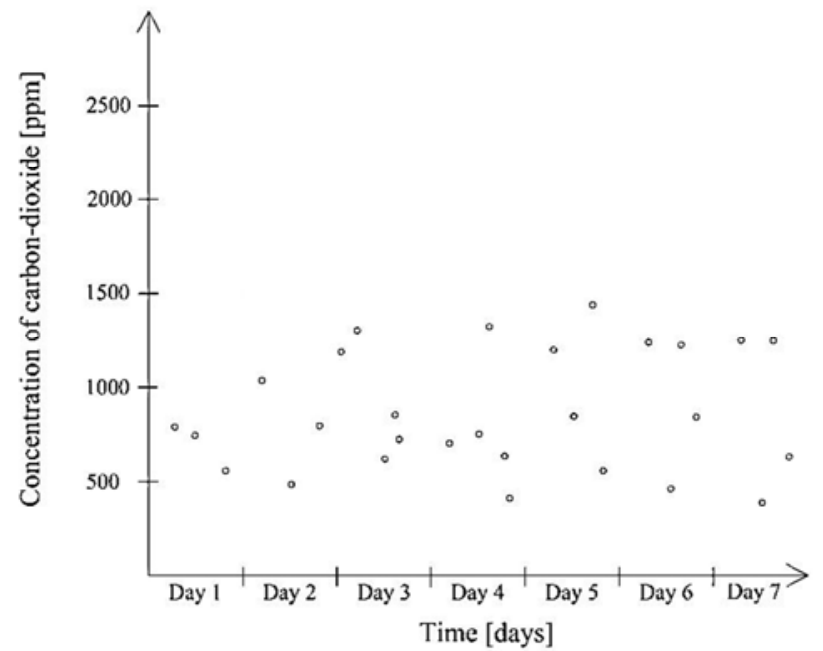

Fig. 5. Carbon-dioxide levels in Apartment \#2 


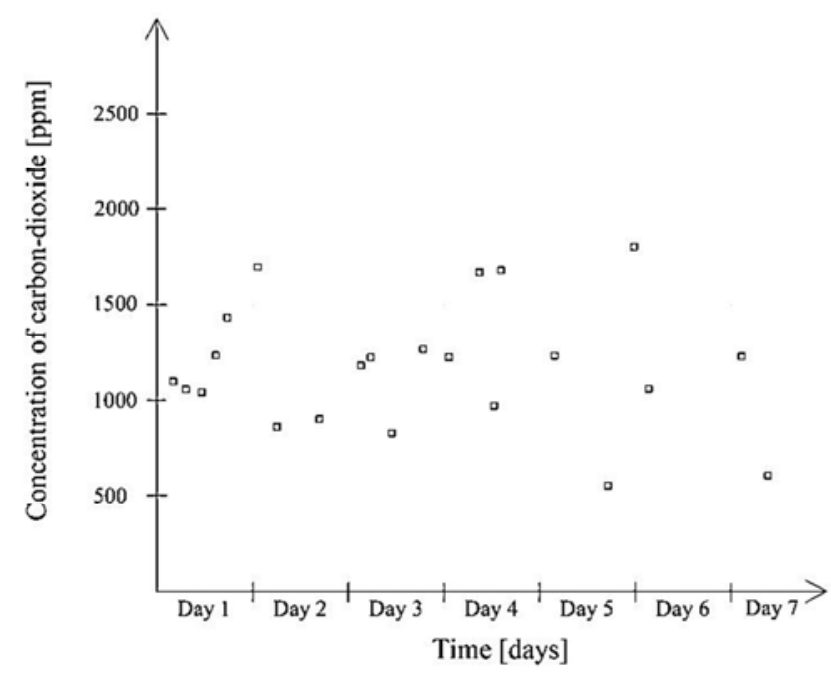

Fig. 6. Carbon-dioxide levels in Apartment \#3

In the case of apartment \#2, the highly insulated, air tight wall and window construction led to several geometrical and material thermal bridges, which, combined with rather small floor area resulted in extremely high carbon-dioxide values (different standards give 600, 1000 or $1200 \mathrm{ppm}$ as a top limit for carbon-dioxide level from a health point of view). Based on additional information gathered from the inhabitants, it is also known that they do not pay attention to adequate natural ventilation.

In case of apartments \#1 and \#3, the buildings are not newly built energy efficient buildings, nor has an energy-efficient retrofit been conducted yet, the wall structure is not so airtight. In addition, the occupants have been focusing more on natural ventilation, than the inhabitants of apartment \#2. Therefore in these two cases the air exchange rate is higher, which resulted in lower carbon-dioxide levels, and in general, better IAQ.

When Relative Humidity (RH) values are evaluated (see Fig. 7), values between 40$60 \%$ are recommended in residential interiors. However, based on occupant feedback, $50 \% \mathrm{RH}$ and above might be uncomfortable if combined with higher indoor air temperature. The measurement values show that RH values in apartment \#2 and \#3 are within this range, but \#1 has higher values. This is because these results were taken during a period of humid, rainy day, which affected the indoor environment.

Fig. 8 shows the values of indoor Temperature $(T)$. Higher indoor temperatures appear in apartment \#1. The reason behind this is that this home is heated with central heating, which has a fixed thermal performance and fixed monthly fee. In the other two cases the apartments are heated with their own gas systems. The advantage of this solution is that the temperature can be locally controlled. This is a more expensive solution, so the inhabitants chose to set the thermostat to $20^{\circ} \mathrm{C}$. 


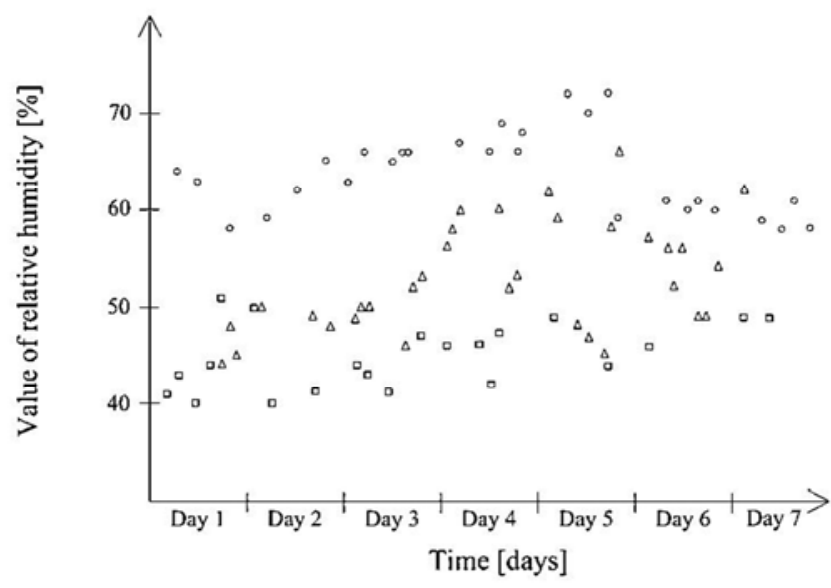

Fig. 7. Relative humidity levels in the residential interiors (circles - apartment \#1, triangles - apartment \#2, squares \#3)



Fig. 8. Indoor temperature in the residential interiors

If the IAQ results of the residential interiors are being evaluated as a system, interesting information appears. Since there is not any mechanical ventilation in these apartments, the carbon dioxide values are not just showing the content, predicting the content of other volatile organic compounds, but are a good indicator for air exchange rate, as well. The higher the carbon-dioxide values, the lower the air exchange rate, 
which will result in poor IAQ and will have another, complex effect, described in details in the following paragraphs.

\section{Conclusion}

Based on the IAQ measurements and occupant feedback it is seen, that an adequate ventilation rate should be ensured to achieve healthy IAQ. The highly insulated, airtight façade constructions will result in poor IAQ, and high levels of carbon-dioxide and relative humidity, which might lead to development of mould on the interior surface of the thermal bridges. The use of mechanical ventilation should be considered, because if the ventilation system depends on natural ventilation only, the responsibility of the occupants is large. This is an important issue, especially in case of energy-conscious retrofit of residential buildings or when a new, airtight construction is built.

In general it can be seen after the measurements that good IAQ in residential interiors depend on the type, construction and details of the façade, on the type and amount of air exchange and on occupant behavior.

\section{Further research}

Additional research is needed to replicate the measurements with equipment that can continuously record and save the measurement values. Research steps are also needed to further investigate the complexity of IAQ, for instance measurement of other contaminants and the rate of air exchange. Larger scale measurements should be conducted, for instance several apartments of one multifamily building should be investigated at the same time (e.g. using wireless monitoring systems).

Besides the on-site measurements, detailed numerical calculations about the behavior of thermal bridges are under development.

Combining the results of this and the previous and ongoing measurements and research more information can be gathered regarding overall IAQ and the relationship between building construction and building physics (e.g. the effect of energy-efficiency retrofits), the ventilation and occupant behavior.

\section{Acknowledgement}

This research was supported by Prince Sultan University, Riyadh, Kingdom of Saudi Arabia, College of Engineering, Department of Interior Design and Architecture. The Author would like to thank the occupants of the apartments for making them available to conduct the measurements and their help in collecting measurement data and the additional information. 


\section{References}

[1] Sarbu I., Sebarchievici C. Aspects of indoor environmental quality assessment in buildings, Energy and Buildings, Vol. 60, 2013, pp. 410-419.

[2] Szkordilisz F., Kiss M. Passive cooling potential of alley trees and their impact on indoor comfort, Pollack Periodica, Vol. 11, No. 1, 2016, pp. 101-112.

[3] Heinzerling D., Schiavon S., Webster T., Arens E. Indoor environmental quality assessment models: A literature review and a proposed weighting and classification scheme, Building and Environment, Vol. 70, 2013, pp. 210-222.

[4] Frontczak M., Wargocki P. Literature survey on how different factors influence human comfort in indoor environments, Building and Environment, Vol. 46, 2011, pp. 922-937.

[5] Mitchell C. S., Zhang J., Sigsgaard T., Jantunen M., Lioy P. J., Samson R., Karol M. H. Current state of the science: Health effects and indoor environmental quality, Environmental Health Perspectives, Vol. 115, No. 6, 2007, pp. 958-964.

[6] Liptak-Varadi J., Széll M., Szabó J., Szabó A., Vanya M., Szili K., Kató L. The healthy environment - The model of residential microclimate, (in Hungarian) Építés - Épitészet, Vol. 41, No. 3-4, 2013, pp. 271-282.

[7] Liang H. H., Chen C. P., Hwang R. L., Shih W. M., Lo S. C., Liao H. Y. Satisfaction of occupants toward indoor environment quality of certified green office buildings in Taiwan, Building and Environment, Vol. 72, 2014, pp. 232-242.

[8] Kwok A. G., Grondzik W. T. The green studio handbook - Environmental strategies for schematic design, Taylor\&Francis, 2011.

[9] Krajcik M., Takacs J. Ventilation intensity in a high-rise building after complete retrofit of its envelope, Pollack Periodica, Vol. 11, No. 2016, pp. 91-100.

[10] Kapalo P., Paulovika A. Evaluation of ventilation on indoor environment, quality by means of multi-criteria methodology, International Review of Applied Sciences and Engineering, Vol. 3, No. 2, 2012, pp. 163-165.

[11] Berk J. V., Young R. A., Brown S. R., Hollowell C. D. Impact of energy-conserving retrofits on indoor air quality in residential housing, Lawrence Berkeley Laboratory, University of California, 1981.

[12] http://www.conrad.com/ce/en/product/101300/Voltcraft-CO-60-Air-Quality-Indicator, (last visited 14 December 2015). 